\title{
Perancangan Robot Pemadam Api Hexapod
}

\author{
Robi Darwis $^{1}$, Indrawan Arifianto ${ }^{1}$, Anwar Mujadin $^{1}$, Suci Rahmatia ${ }^{1}$ \\ ${ }^{1}$ Program Studi Teknik Elektro, Fakultas Sains dan Teknologi, Universitas Al Azhar Indonesia \\ Jalan Sisingamangaraja, Komplek Masjid Agung Al Azhar, Kebayoran Baru, Jakarta Selatan, 12110 \\ Penulis untuk Korespondensi/E-mail: suci@uai.ac.id,
}

\begin{abstract}
Abstrak Seiring perkembangan teknologi yang begitu pesat, robot-robot cerdas bermunculan dan diciptakan untuk memudahkan dan meringankan pekerjaan manusia. Mesin robot yang semakin pesat perkembangannya pada dasarnya membantu manusia dalam beraktifitas sehari-hari sehingga pekerjaan manusia lebih efisien. namun seiring perkembangan itu harus diimbangi dengan sumber daya manusia yang mampu menguasai teknologi tersebut tidak hanya menggunakannya. Paper ini membahas perancangan robot yang dibuat oleh Mahasiswa Universitas Al Azhar Indonesia guna meningkatkan kemampuan dan pengetahuan dalam bidang teknologi khususnya di bidang robotik. Robot yg dibuat ini berfungsi untuk memadamkan api. Robot ini merupakan jenis hexapode, yaitu robot jenis laba-laba berkaki enam yang menggunakan servo dan dijalankan menggunakan Android dan sensor. Namun fungsi pemadam api belum berjalan dengan baik karena servo motor yang digunakan terlalu besar sehingga power pada robot hanya mampu mengangkat ke-enam kaki robot selama dua detik.
\end{abstract}

Abstract- Along with the rapid development of technology, intelligent robots have sprung up and created to facilitate and ease human work. Robot machines that are increasingly rapidly developing basically help humans in their daily activities so that human work is more efficient. but along with that development must be balanced with human resources who are able to master the technology not only use it. This paper discusses the design of robots made by Students of Al Azhar University in Indonesia in order to improve their abilities and knowledge in the field of technology, especially in the field of robotics. The robot that is made serves to extinguish the fire. This robot is a type of hexapode, which is a type of six-legged spider that uses servo and is run using Android and sensors. But the fire extinguisher function has not gone well because the servo motor that is used is too large so that the power on the robot is only able to lift the robot's six legs for two seconds..

Keywords- Fire robot, Hexapod robot, Arduino, Servo motor

\section{PENDAHULUAN}

$\mathrm{P}$ erkembangan teknologi di era modern ini sangat pesat. Saat ini Ilmu Pengetahuan dan Teknologi (IPTEK) menjadi hal terpenting di setiap aspek kehidupan sehari-hari. Hampir setiap aspek kehidupan telah tersentuh oleh kacanggihan teknologi, seperti di bidang kedokteran, pendidikan, industri bahkan di bidang pertanian. Perkembangan teknologi ini telah mentransformasikan semua kegiatan manusia yang dilakukan secara tradisional secara bertahap ke arah yang modern. Teknologi yang diciptakan dan dikembangkaan saat ini sematamata adalah untuk meringankan dan memberikan kemudahan kegiatan manusia sehingga terciptanya efektifitas produksi, efisiensi kerja dan ketepatan sistemik pada setiap aspek bidang kehidupan.
Jika dilihat dari sejarah, perkembangan teknologi secara besar-besaran diawali ketika terjadi Revolusi Industri Eropa. Sebelum terjadinya Revolusi ini sistem perekonomian sangat bergantung pada system ekonomi agraris. Namun setelah terjadinya Revolusi Industri Eropa ini terjadi perubahan pola hidup masyarakat Eropa. Perubahan ini ditunjukan dengan digunakan tenaga mesin sebagai alat produksi menggantikan tenaga hewan dan manusia. Sebelum dikenal alat mekanis dan otomatis manusia masih bekerja dengan menggunakan alat-alat manual dan masih mengandalkan kecepatan tangan dan kaki manusia. Dari situlah perkembangan teknologi dan mesin-mesin menakjubkan bermunculan untuk memudahkan kegiatan manusia, salah satunya adalah yang sangat familiar adalah robot. [1] 
Seiring perkembangan teknologi yang begitu pesat, robot-robot cerdas bermunculan dan diciptakan untuk memudahkan dan meringankan pekerjaan manusia. Mesin robot yang semakin pesat perkembangannya pada dasarnya membantu manusia dalam beraktifitas sehari-hari. Penggunaan robot dapat membantu kegiatan atau pekerjaan manusia agar efisien dalam waktu penyelesaian, serta mengurangi tingkat resiko kecelakaan kerja. Beberapa pekerjaan manusia yang sering menggunakan bantuan mesin robot masuk kategori pekerjaan yang sukar, berbahaya dan membosankan karena membutuhkan tingkat ketelitian yang tinggi.

Walaupun demikian, robot itu sendiri tetap masih membutuhkan interaksi manusia dalam operasinya sehingga muncul suatu paradigma tentang bagaimana mendesain suatu sistem interaksi antara manusia dengan robot yang ergonomis. Hal ini tentu sangat bergantung pada sumber daya manusia. Kemajuan teknologi saat ini khususnya di bidang robotik harus diimbangi dengan kemampuan sumber daya manusia yang dapat menguasai teknologi tersebut. Saat ini perkembangan teknologi di bidang robotik masih banyak bermunculan dari negara negara maju. Oleh karena itu, pada paper ini akan dibahas perancangan robot pemadam api berjenis hexapod guna melatih kemampuan dan menguasai ilmu pengetahuan dan teknologi terutama dalam bidang robotik. Hasil perancangan ini diharapkan dapat dijadikan rujukan atau contoh untuk pembuatan dan pengembangan robot-robot berikutnya agar perkembangan teknologi di bidang robotik dapat berkembang pesat di Indonesia dengan diiringi kemampuan sumber daya manusia yang mumpuni.

\section{METODE}

\section{Perancangan dan Pembuatan Robot}

Perancangan robot ini dirancangan untuk memadamkan api dengan jenis robot hexapod, yaitu robot jenis laba-laba berkaki enam yang menggunakan servo dan dijalankan menggunakan Android dan sensor.

Perancangan dan pembuatan robot ini disusun melalui beberapa tahapan mulai dari disain robot sampai dengan tahap pemrograman.

\section{Desain Robot}

Gambar di bawah ini merupakan prototype dari desain keseluruhan robot pemadam api yang dibuat.

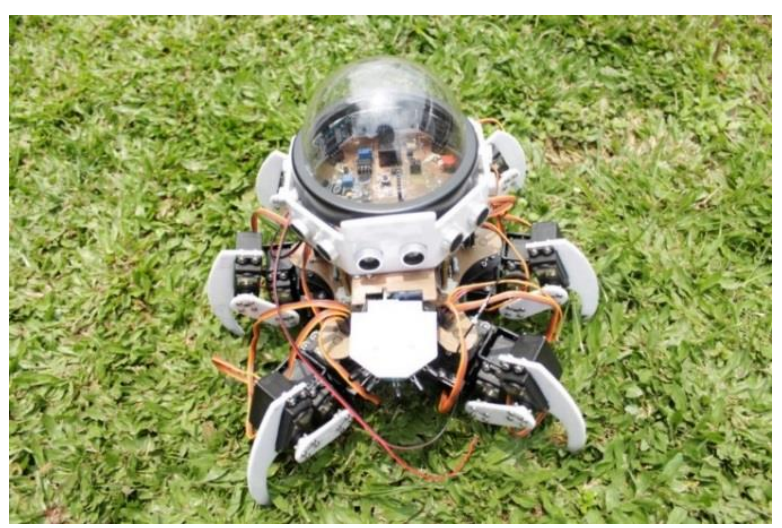

Gambar 1. Prototype desain keseluruhan robot

\section{Sistem Kontrol}

Sistem kendali robot berkaki enam ini dilengkapi dengan 3 buah mikrokontroller. Masing masing mikrokontroller memiliki fungsi dan tugas yang berlainan seperti otak manusia. Mikrokontroler 1 (otak kanan) bertugas sebagai aktuator pengendali 6 buah motor servo penggerak kaki robot. Mikrokontroler 2 (otak kiri) bertugas sebagai pemindai (sensor) seperti pemindai jarak (Ultrasonik), pemindai cahaya (fotodioda), pemindai suhu (PIR), pemindai tracking line (Optocoupler), dan pemindai benturan (limit switch). Sedangkan Mikrokontroler 3 berfungsi sebagai analisa dan komando. Semua mikrokontroler yang digunakan adalah arduino mikro seperti yang diperlihatkan pada gambar berikut:

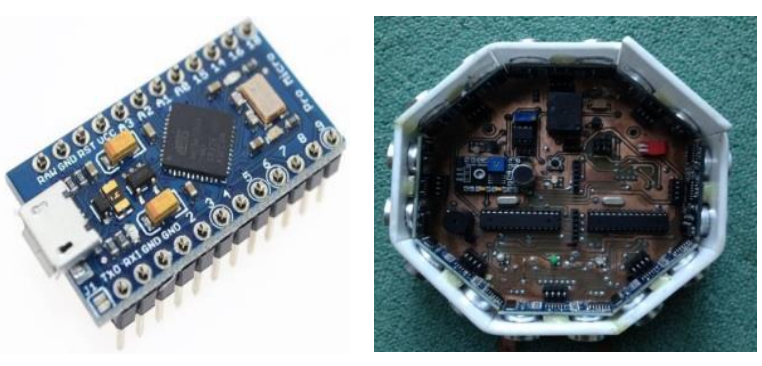

Gambar 2. Mikrokontroller

\section{Sistem Sensor}

Gambar di bawah ini merupakan rancangan sistem sensor yang terpasang pada robot pemadam api tersebut. 


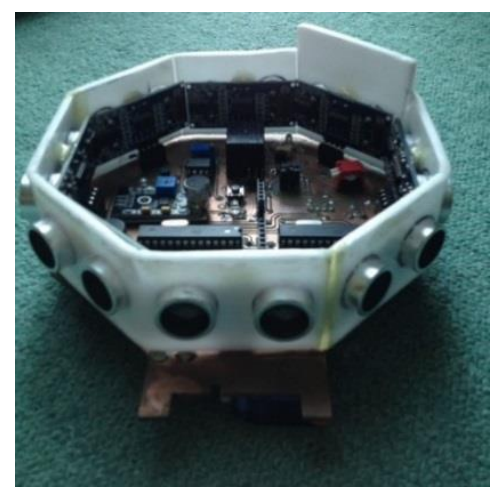

Gambar 3. Sistem Sensor

Algoritma

Robot dilengkapi dengan algoritma (low level software) yang tertanam dalam mikrokontroler komando (mikrokontroler 3). Home base posisi ditrack menggunakan perubahan jarak pergerakan $\mathrm{X}$ dan Y robot. Setiap pergerakan X dan Y di memori kemudian dikalkulasi sehingga robot mampu kembali ke home base. Robot ini dilengkapi dengan 4 buah dip switch algoritma. Dari keempat dip switch tersebut di embbed menjadi 16 kemungkinan pemilihan database low level software. Robot pemadam api ini dilengkapi dengan sensor suara sebagai Sound Aktivation, Flame detector dan PIR Sensor sebagai pendeteksi api dan suhu, Sensor distance sebagai pendeteksi dinding dan rintangan serta mengontrol jarak antara robot ke dinding dan juga lilin.

Kriteria algoritma ringkas dijelaskan sebagai berikut:

a) Robot diaktifkan menggunakan perangkat sound activation. Jika sound activation aktif ditandai maka indikator LED berwarna hijau menyala, jika tidak maka lampu tetap mati.

b) Robot mendeteksi keberadaan api dan suhu api dengan menggunakan Flame Detector (Fototransistor dan PIR Sensor).

c) Jika terdeteksi keberadaan api maka indikator LED merah menyala, jika api mati maka indikator LED mati. Robot me-record track (X dan Y) dan jarak yang ditempuh selama perjalanan menuju api.

d) Robot berjalan mencari titik api. Robot berjalan maju dengan prinsip berjalannya lomba bakiak, kaki kaki kanan dan kiri berjalan bergantian namun serempak antara kaki depan, tengah, dan belakang.

e) Robot mendeteksi keberadaan dinding atau furnitur. Jika ada dinding atau furnitur terdeteksi dengan jarak $3 \mathrm{~cm}$, maka robot akan mencari celah yang tidak terhalangi oleh dinding dan furnitur tersebut.

f) Robot menentukan arah ke kanan atau ke kiri memanfaatkan informasi posisi api lilin oleh flame detector.

g) Langkah b s.d. f terus berulang jika belum menemukan api.

h) Jika robot mendeteksi api dengan jarak $3 \mathrm{~cm}$, maka robot menyemprotkan air ke lilin tersebut.

i) Jika api mati maka indikator LED warna hijau mati.

j) Robot kembali ke posisi Home dengan bantuan record data tracking (X dan $\mathrm{Y}$ ) yang telah tersimpan selama perjalanan mencari titik api.

\section{HASIL DAN PEMBAHASAN}

Dalam pelaksanaan Perancangan Robot Kreasi Al Azhar ini terdapat beberapa tahapan dari mulai riset sampai pembuatan. Berikut beberapa hasil perancangan dan pembuatan robot.

Gambar dibawah menunjukkan rancang banggun rangkaian skematik dari robot tersebut. Rangkaian skematik tersebut dibuat software protheus kemudian mencetaknya pada papan PCB. Setelah itu komponen yang dipakai seperti kerangka kaki dan body dipasang pada papan PCB tersebut seperti terlihat pada gambar dibawah.

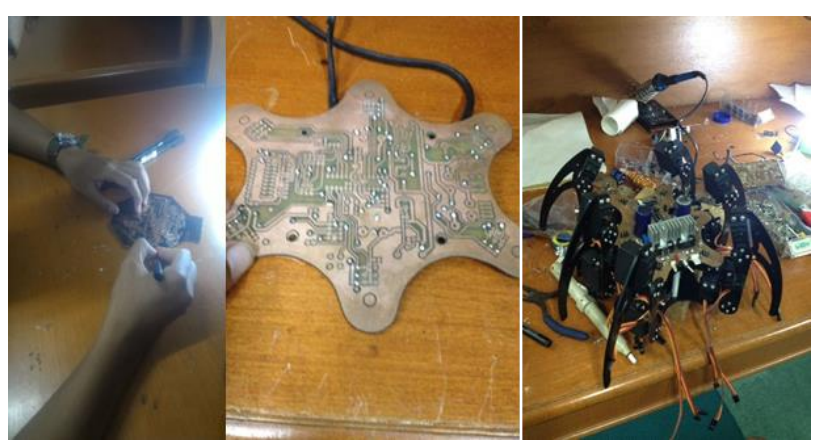

Gambar 4. Proses Pembuatan PCB

Gambar dibawah menunjukkan bagian utama dari robot. Bagian tersebut adalah mikrokontroler yang terpasang pada bagian atas dan bagian penggerak yaitu bagian body dari robot tersebut. Bagian atas atau bisa disebut bagian kepala dari robot tersebut dilengkapi dengan sensor ultrasonik yang berguna untuk mendeteksi obstacles atau penghalangpenghalang yang ada di sekitar robot. Sedangkan bagian body adalah bagian untuk menggerakkan robot tersebut. Bagian ini terdiri 
dari beberapa servo yang membentuk kaki robot tersebut

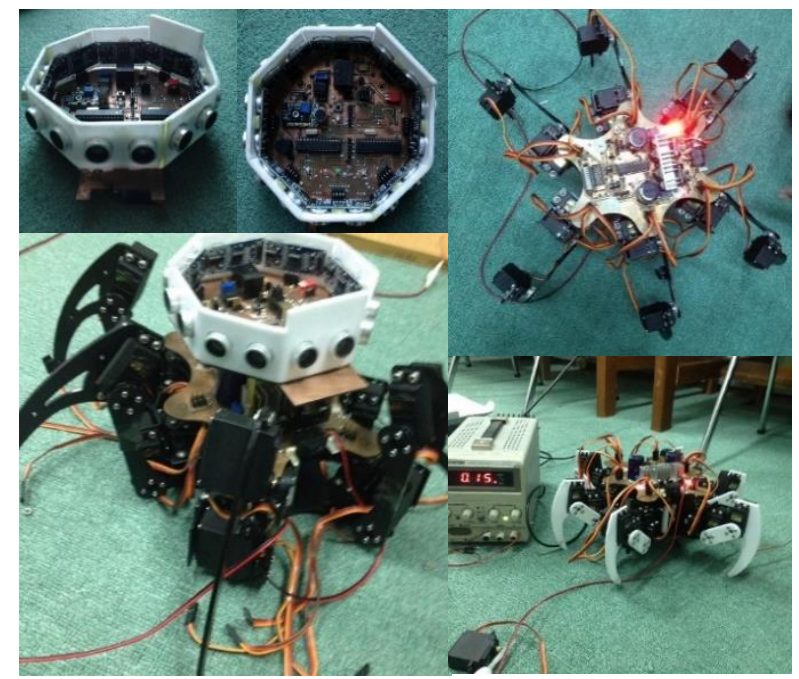

Gambar 6. Desain Robot Pemadam Kebakaran

\section{KESIMPULAN}

1. Perancangan Robot Kreasi Al Azhar ini belum sempurna dalam hal kekurangan komponen dan pemrograman. Sehingga masih belum bisa dijalankan sesuai dengan fungsinya yaitu pemadam api.

2. Servo motor yang digunakan terlalu besar sehingga power pada robot hanya mampu mengangkat 2 detik ke-enam kaki robot.

3. Perancangan Robot Kreasi Al Azhar ini diharapkan mampu memberikan dampak positif bagi mahasiswa, sehingga kegiatan ini dapat mendongkrak minat dan bakat mahasiswa dan juga meningkatkan pengetahuan tentang robotika agar dapat bersaing di bidang robotika. Selain itu juga diharapkan pengetahuan tentang robotika dapat diterapkan pada teknologi yang dapat memudahkan pekerjaan manusia.

\section{REFERENSI}

[1] A. Hindratmo, "Pentingnya Peranan Mesin Robot Bagi Manusia Baik Dalam Dunia Industri maupun Kehidupan Sehari-hari", Surabaya: ITS, 2012.

[2] R. Crhistyant,"Robot dan Kehidupan Manusia",https://www.kompasiana.com/ryan can/55c8968f707a61a72205f0cb/robot-dankehidupan-manusia?page=all, Agustus 2015. [Diakses 20 April 2018].

[3] A. Begam,"Line Following Robot without Using Microcontroller",International Journal on Recent and Innovation Trends in Computing and Communication, Vol. 2, 2014.

[4] A. Purnama, "Prinsip Kerja Motor DC", Februari 2018, [Online], Dapat diakses: http://elektronika-dasar.web.id/prinsipkerja-motor-dcl. [Di akses 20 April 2018].

[5] Next System Robotics Learning Center, "Motor DC dan Gearbox", Next System Robotics Learning Center, September 2010, http://nextsys.web.id/edukasi/tag/motor-dcgearbox. [Di akses 20 April 2018].

[6] A. Rahmat, "Mengenal Macam-Macam Jenis Baterai", Desember 2014 [Online], Tersedia : https://kelasrobot.com/mengenal-macammacam-jenis-baterail. [Di akses 24 April 2018].

[7] A. W. Ibrahim, T. W. Widodo, T. W. Supardi, "Sistem Kontrol Torsi pada Motor DC",Indonesian Journal of Electronics and Instrumentations Systems, Vol.6 No.1, 2016. 